4.

Derecho constitucional 



\title{
PREVENCIÓN, REPRESIÓN Y CONTROL DEL DOPAJE FRENTE AL DERECHO A LA INTIMIDAD DEL DEPORTISTA EN EL MARCO JURÍDICO ESPAÑOL*
}

[Doping Prevention, Repression and Control Versus the Right to Privacy of the Sportsperson in the Spanish Legal System]

\author{
Elena Atienza Macías** \\ Universidad de Deusto, Bilbao, España
}

\begin{abstract}
ReSUMEN
El dopaje es abordada desde dos dimensiones distintas: de un lado, se estudia el régimen jurídico de su prevención y represión; y, de otro lado, se advierte la colisión que desencadena el mecanismo del control antidopaje con un derecho fundamental como es la intimidad del deportista. En España, sobre la materia rige la Ley Orgánica $N^{\circ} 7 / 2006$ de Protección de la Salud y de Lucha contra el Dopaje en el Deporte. Ahora bien, se presenta el problema consistente en que la legislación antidopaje a nivel mundial y español habilita a los profesionales sanitarios y a otras
\end{abstract}

\begin{abstract}
Doping is addressed from two different scopes: on one hand, the legal regulations for prevention and repression are studied; on the other hand, the clash between the anti-doping control mechanism and a fundamental right such as the sportsperson's privacy is noted. The Organic Act No. 7/2006 on Protection of Health and Fight against Doping in Sports rules on this matter in Spain. Well now, the problem arises when the anti-doping legislation worldwide and in Spain, which enables some healthcare professionals and other people involved, to carry out several
\end{abstract}

ReCibido el 22 de febrero y aCEPTADo el 20 de mayo de 2013

* El presente trabajo se enmarca dentro del Programa para la Formación de Personal Investigador de la Universidad de Deusto al que la autora está adscrita.

** Investigadora en la Cátedra Interuniversitaria de Derecho y Genoma Humano, Universidad de Deusto y Universidad del País Vasco UPV/EHU. Dirección postal: Avda. de las Universidades, 24, 48007 Bilbao, España. Correo electrónico: elena.atienza@deusto.es y www.bioderecho.eu 
personas implicadas a efectuar una serie de operaciones "antidoping" que pueden llegar a entrar en conflicto con el derecho fundamental a la intimidad del deportista. Es, por ende, pertinente plantearse si una de estas operaciones, como es el deber de localización permanente, queda suficientemente justificada en función de proteger la salud del deportista.

Palabras clave

Dopaje - Protección de la salud - Control antidopaje - Localización permanente - Derecho a la intimidad Protección de datos. anti-doping operations that may conflict with the sportsperson's fundamental right to privacy. For this reason, it is pertinent to raise the issue if one of these operations, such as the duty of permanent localization, is sufficiently justified in terms of protecting the sportsperson's health.

\section{KEYWORDS}

Doping - Health Protection - Antidoping Control - Permanent Localization - Right to Privacy - Information protection.

\section{MARCo general de LA LUCHA ANTIDOPAJE EN EL ÁMbito DEPORTIVO. JUSTIFICACIÓN DE LA POLÍTICA ADOPTADA: VALORES Y BIENES JURÍDICOS EN JUEGO.}

Es incuestionable en nuestros días que el deporte ha adquirido una dimensión espectacular proyectada en todos los terrenos -social, cultural, económico, jurídico, ético e indeseablemente incluso político-, llegando a convertirse, actualmente, en un aspecto consustancial al sistema de vida de los ciudadanos. En este sentido, la práctica deportiva ha calado de tal manera en el tejido social que se ha integrado como parte importante de la vida diaria, de la actividad cotidiana de millones de personas en todo el mundo. Íntimamente unido a todo ello, el fenómeno deportivo presenta la virtualidad de trascender las fronteras de un Estado ${ }^{1}$, es decir, con las prácticas deportivas se facilitan las relaciones entre los diferentes países fomentando el entendimiento internacional y convirtiéndose, por ende, en paradigma de la definición de muchos de ellos y en estandarte del propio desarrollo de los países a los que representa. Desde esta perspectiva, la transnacionalización o globalización de la economía y de toda la sociedad en su conjunto ha llevado aparejada una creciente dimensión transnacional de la actividad

${ }^{1}$ Véase sobre este tema Bermejo Vera, José, Régimen jurídico de la prevención y control del dopaje en el deporte, en RoMEo CASABONA, Carlos María (editor). Más allá de la salud. Intervenciones de mejora en humanos (Bilbao -Granada, Cátedra Interuniversitaria de Derecho y Genoma Humano - Comares, 2012), pp. 135-149; para más detalle puede verse de este mismo autor su obra monográfica Constitución y Deporte (Madrid, Tecnos, 1998). 
deportiva. Todo ello ha implicado que el Derecho deportivo haya ganado ya una autonomía y entidad propias como disciplina jurídica, ofreciendo no obstante la actividad deportiva numerosas perspectivas de análisis: desde la Filosofía, (Bio)Ética, Sociología, Psicología, ciencias médicas (en concreto la especialidad de la Medicina Deportiva) y por supuesto desde el Derecho.

En el escenario de globalización descrito, irrumpe con fuerza el dopaje o doping (en su versión anglosajona), como uno de los asuntos más controvertidos y de candente actualidad en el seno del deporte contemporáneo. Así, partimos de las contundentes palabras de O'Leary²: "Los escándalos de dopaje arruinan las carreras de los deportistas, pueden llevar a la bancarrota a consejos de administración, vulnerar libertades individuales, amenazar a la supervivencia económica" así como "minar el Movimiento Olímpico". El dopaje alcanza, por ende, en nuestros días la categoría de problema global que acompaña a los acontecimientos deportivos internacionales que se llevan a cabo en todo el mundo. En efecto, citas tan significativas en el calendario deportivo -como los Juegos Olímpicos recientemente celebrados, el pasado verano de 2012 en Londres o los próximos Juegos Olímpicos que tendrán lugar en Río de Janeiro en 2016-, no han quedado ni quedarán exentas de la sombra del dopaje, en las que, previsiblemente, jugará un papel importante.

Y es que la relevancia y oportunidad del tema puede apreciarse a la luz de la proliferación de graves casos de doping tanto en España como en el resto del mundo que lo han situado en un primer plano en los medios de comunicación y en las agendas de los responsables políticos y deportivos. Ciertamente, en los últimos años esta problemática viene adquiriendo un protagonismo que va in crescendo a la vista de casos tan notables como el de Ben Johnson, Marion Jones, Marco Pantani o el de Lance Armstrong -el último de los casos más sonados de dopaje positivo en el deporte mundial- entre otros, hasta el más reciente y controvertido en el panorama español del ciclista Alberto Contador. A todo ello se une la enorme polémica suscitada en torno a la limpieza o "fair play" del deporte puesta últimamente en España -con las tan divulgadas Operación Puerto ${ }^{3}$ y Operación Galgo, envolviendo esta

\footnotetext{
${ }^{2}$ Reflexiones de este cariz en O'Leary, J., Drugs and Doping in Sport. Socio-Legal Perspectives (London, Cavendish Publishing, 2001).

${ }^{3}$ Véase sobre esta operación contra el dopaje en el deporte de élite realizada en España, Hardie, Martin, No va sobre la sangre: Operación Puerto y el fin de la modernidad, en Revista Aranzadi de Derecho de Deporte y Entretenimiento, 30 (Pamplona, Editorial Aranzadi, 2010), pp. 123-141. Se recomienda una consulta asimismo de Ventas SaStre, Rosa, Eventual delito contra la salud pública: comentario al Auto de la Audiencia Provincial de Madrid (sección 5a), de 12 de enero de 2009, por el que se reabre la "Operación Puerto", en Revista Aranzadi de Derecho de Deporte y Entretenimiento,
} 
última a la conocida atleta Marta Domínguez y a un sinfín de profesionales sanitarios y entrenadores- muy en tela de juicio.

Así las cosas, el planteamiento del autor reseñado, $\mathrm{O}^{\prime}$ Leary, -cuyas afirmaciones, no obstante, pueden ser tildadas de excesivas-, nos sirve como punto de partida para este estudio. Efectivamente, cuando nos adentramos en el dopaje encontramos consideraciones sumamente delicadas que trascienden a problemas gravísimos y complejos, en un trasunto decididamente multidisciplinar y por consiguiente, impregnado de reflexiones de diversa índole: económico, mediático y político, que son las que más saltan a la luz, pero también las que subyacen en la órbita sanitaria. Desde este punto de vista, nos referimos al término "salud" en sentido amplio ${ }^{4}$ que comprende no sólo la salud física, la cual ha sido considerada en el seno del dopaje más o

Editorial Aranzadi, 26 (Pamplona, 2009), pp. 345-351. Y para un análisis sobre los delitos implicados en la mencionada Operación Puerto véase: Vernet Perna, Beatriz, Delitos relacionados con el dopaje en el deporte (Madrid, Instituto Universitario de Investigación sobre Seguridad Interior, UNED, 2008), concretamente el capítulo IV "Investigación operativa: Operación Puerto", pp. 63-72.

${ }^{4}$ La definición más conocida de salud es la propuesta por la Organización Mundial de la Salud (OMS) en 1946, concibiendo ésta como "un estado completo de bienestar fisico, mental y social, y no solamente la ausencia de enfermedad”. En este sentido: BANDrÉs Moya, Fernando, voz "Salud" (técnico), en Romeo Casabona, Carlos María (director), Enciclopedia de Bioderecho y Bioética (Bilbao - Granada, Cátedra Interuniversitaria de Derecho y Genoma Humano - Comares y el Instituto Roche, 2011), II, pp. 1479-1481, señala que esa identificación de salud con estado de bienestar abarca el ámbito físico (cuerpo), el psíquico (mente), y un tercero que sería el sociológico (derecho). Este último aspecto se refiere al derecho a la salud que se recoge en el Derecho internacional como un derecho humano. Así, el propio Pacto internacional de derechos económicos, sociales y culturales en su artículo 12 dispone: "reconocen el derecho de toda persona al disfrute del más alto nivel posible de salud mental y física". A todo ello se suma que la propia Constitución española de 1978, establece una vinculación entre deporte y salud en su artículo 43 CE: "1. Se reconoce el derecho a la protección de la salud. 2. Compete a los poderes públicos organizar y tutelar la salud pública a través de medidas preventivas y de las prestaciones y servicios necesarios. La Ley establecerá los derechos y deberes de todos al respecto. 3. Los poderes públicos fomentarán la educación sanitaria, la educación fisica y el deporte. Asimismo facilitarán la adecuada utilización del ocio". 
menos adecuadamente ${ }^{5}$, sino también mental o psíquica ${ }^{6}$, que no ha recibido hasta el momento toda la atención e importancia que merece y de ello su necesidad de estudio más pormenorizado (no obstante resultaría ciertamente ambicioso dar cuenta cabal de todo ello en este pequeño trabajo que responde además a un propósito distinto).

En efecto, junto con esta vertiente de protección de la salud del deportista, la garantía de igualdad de oportunidades entre competidores y la preservación de los valores deportivos, se configuran como los tres ejes centrales que justifican el régimen antidopaje ${ }^{7}$. Lo concerniente a la igualdad

${ }^{5}$ Decimos más o menos porque en la doctrina contemporánea está mayoritariamente extendida la idea de que la lucha contra el dopaje es un medio o conducto en pro de preservar los valores sociales inherentes al deporte, sin perjuicio de que al mismo tiempo y, parece que de forma colateral, se pretenda salvaguardar la salud del deportista. Siguiendo este planteamiento Auneau, G., Dopage et mouvement sportif (Voiron, Presses Universitaires du Sport, 2001), pp. 7 ss., considera especialmente los valores sociales que encierra el deporte, siendo éste el fin principal al que servirían las políticas antidopaje, y de forma paralela y no excluyente la protección de la salud del deportista. En esta línea también se pronuncia la Sentencia del Tribunal de Primera Instancia de la Comunidad Europea de 30 de septiembre de 2004, asunto T-313/02, por la que se resuelve el recurso interpuesto por dos nadadores contra la Decisión de la Comisión Europea de no declarar contrarias al Derecho de la competencia las normas antidopaje aplicadas por la anteriormente mencionada FINA y el Comité Olímpico Internacional (COI). De acuerdo con el tenor literal de este pronunciamiento: "[...] la lucha contra el dopaje pretende, en primer lugar, mantener el espiritu deportivo (el juego limpio), sin el cual el deporte deja de ser deporte, independientemente de que se practique por aficionados o por profesionales. Este objetivo, con un mero carácter social, justifica por si sólo la lucha contra el dopaje. En segundo lugar, en la medida en que los productos para el dopaje no están exentos de efectos fisiológicos negativos, esta lucha tiene por objeto cuidar la salud de los atletas $[. .$.$] ". De tal manera que la protección de la salud quedaría relegada a un segundo$ plano, casi como un efecto colateral.

${ }^{6}$ Véase la presentación que elaboró la autora del presente trabajo en torno al dopaje y la salud mental con ocasión del II Seminário Hispano-Brasileiro de Direito Biomédico: "Direito Biomédico, Neurociências e Psiquiatria. Aspectos Teóricos e Práticos", celebrado en Belo Horizonte, Brasil (Pontificia Universidad Católica de Minas Gerais PUC Minas), los días 22, 23 y 24 de mayo de 2012. Atienza Macías, Elena, Dopajey enfermedad mental: más allá de la responsabilidad del deportista, disponible en: http:// www.cebid.com.br/ii_sem_hispano_brasileiro/dra_elena.pdf [última consulta: 15 de marzo de 2013].

${ }^{7}$ La doctrina mayoritaria se refiere a estos tres fines principales como justificadores de las políticas antidopaje. Así, Prokop, C., Die Grenzen der Dopingverbote (BadenBaden, Nomos Verlagsgesellschaft, 2000), pp. 233 ss., alude a la garantía de igualdad de oportunidades entre competidores, a la protección de la salud del deportista y preservación de los valores deportivos, de esta forma sostiene que existen motivos suficientes para fundamentar la lucha contra el dopaje simultáneamente en los tres objetivos, lo que lleva a sostener la compatibilidad de todos estos fines. En la misma línea, pero 
de oportunidades, se incardina en la idea del deporte como empresa -de hecho es un "gran negocio" - y por tanto en las razones económicas ${ }^{8}$ que, como indicamos, mueven al mismo. Los fraudes en la práctica deportiva y el asunto de la competencia desleal son, en consecuencia, problemas que se traslucen en este ámbito. Por otra parte, en cuanto a la preservación de los valores deportivos, entra en juego la relación entre la Ética y el Deporte? constituyendo el dopaje uno de los principales problemas que, desde este estadio, rodean al orden deportivo (profesional y "amateur"), canalizados en el difuso término del "fair play". En este plano, el deporte puede ser visto desde dos ópticas, a saber, como espectáculo y como actividad comercial. Se trata de perspectivas que pueden actuar por separado o solaparse, si bien son estas últimas a las que dedicamos nuestra atención. En principio, un depor-

centrándonos en la Ley Orgánica $\mathrm{N}^{\circ}$ 7/2006, de 21 de noviembre, de Protección de la salud y de lucha contra el dopaje en el deporte, pieza angular de la legislación española reguladora del dopaje; véase Palomar Olmeda, Alberto - Rodríguez García, José, La salud pública y las medidas que afectan a la misma para la luch a contra el dopaje", en Cazorla Prieto, Luis María - Palomar Olmeda, Alberto (directores), Comentarios a la Ley Antidopaje en el Deporte (Pamplona, Aranzadi, 2007), pp. 429 ss. Estos autores estiman que la concepción subyacente en la mencionada ley sitúa la prevención de la salud de las personas que hacen deporte (porque la ley no se limita al deportista profesional) como uno de los valores a preservar junto con el de la pureza de la competición (equivaldría al juego limpio como uno de los vectores al que hemos hecho referencia) y la propia lucha contra la actividad del dopaje que constituye un fraude a las propias reglas del deporte (identificado con la igualdad de condiciones). En igual sentido, Ramos Gordillo, Antonio, Lucha contra el dopaje como objetivo de salud, en Adicciones, 11 (1999) 4, pp. 299-310, quien identifica como tres, los objetivos de la lucha contra el dopaje, a saber: $i$ ) garantizar la ética en el deporte; ii) garantizar la igualdad en las condiciones de la competición, de forma que los resultados dependan básicamente de las condiciones físicas, psicológicas e higiénicas, o lo que es igual su preparación y sus actitudes para este deporte y nunca por la posibilidad de ser superior en razón de la administración de sustancias para mejorar ese rendimiento; y iii) preservar la salud en el sentido de que el ejercicio no debe provocar alteraciones y patologías en el deportista. Existen otras voces que consideran que la prohibición del dopaje sobre la base de las anteriores motivaciones resulta injustificada y que debe, por lo tanto, ser dejada sin efecto. Véase: TAmburrini, C., ¿Qué tiene de malo el dopaje? en Dilemata, 2 (2011) 5, pp. 45-71.

${ }^{8}$ Resalta la doctrina que el aumento del interés por el deporte a nivel económico, con la llegada de cuantiosas sumas de dinero, y el consecuente interés crematístico de algunos organizadores y patrocinadores, son motivos de peso que han llevado a un crecimiento exponencial del dopaje. Véase, entre otros: Rubio, Francisco, El dopaje y la normativa de salud laboral, en Cazorla Prieto, Luis María - Palomar Olmeda, Alberto (directores), Comentarios a la Ley Antidopaje en el Deporte, cit. (n. 9), pp. 518 ss.

${ }^{9}$ Fundamental, Pérez Triviño, José Luis, Ética y deporte (Bilbao, Desclée De Brouwer, 2011), pp. 57 ss. 
tista que acude al dopaje sin el propósito de competir no estaría actuando de forma tal que quebrante algún principio ético o alguna norma de conducta ética. Entendemos que la eticidad del dopaje per se no sería cuestionable. El sugestivo debate respecto de la eticidad del dopaje surge cuando éste se utiliza como medio fraudulento, esto es, con el fin de obtener mejores resultados deportivos que la contraparte -al mismo tiempo que se le induce a error en el sentido de que se le oculta la causa u origen de dichos resultados extraordinarios-, nótese que nos encontramos en un proceso diferente, de competición, donde existirá una relación contractual expresa o tácita.

Con todo y volviendo al tema que nos ocupa, que la protección de la salud se configure como uno de los pilares básicos de la lucha antidopaje no justifica que esta última no tenga límites. En otras palabras, el poder de control antidopaje colisiona directamente con derechos fundamentales, como es el caso del derecho a la intimidad del deportista -quien durante la toma de muestras se ve obligado a proporcionar información sobre su estado de salud y los tratamientos médicos que sigue, lo que supone una palmaria intromisión en su intimidad-ex artículo 18 de la Constitución Española y artículo 8 del Convenio Europeo de Derechos Humanos en el plano internacional, exigiéndose de forma apremiante una ponderación de valores en juego ${ }^{10}$.

\section{LA PROBLEMÁTICA DEL DOPAJE DESDE UNA PERSPECTIVA JURÍDICO-SANITARIA}

\section{Precisiones conceptuales}

El dopaje en el campo deportivo comporta una problemática compleja y multifactorial que trasgrede el simple afán de superación de las limitaciones tanto físicas como psíquicas del deportista en pro de satisfacer ese deseo interno y característico de la especie humana de superación, en cualquier caso legítimo, que le empuja en todos los niveles a competir para alcanzar una posición más "alta"11.

De este modo, el consumo de sustancias con la finalidad de conseguir un

${ }^{10}$ Una manifestación de esta realidad encontramos en Punzón Moraleda, Jesús - SÁnchez Rodríguez, Francisco, Una situación ambivalente del derecho de deporte: la lucha contra el dopaje y la defensa del derecho de intimidad, en Revista jurídica de deporte y entretenimiento: deportes, juegos de azar, entretenimiento y música, 26 (2009), pp. 141-158.

${ }^{11}$ Pérez Monguió, José María, Dopaje, animales y competición deportiva, en MiLlán Garrido, Antonio (coordinador), Régimen jurídico del dopaje en el deporte, Colección "Derecho y Deporte" dirigida por Antonio Millán Garrido (Barcelona, Bosch, 2005), pp. 201-202. 
aumento artificial del rendimiento deportivo, llevando aparejado un menoscabo en la salud, ha estado presente a lo largo de la historia ${ }^{12}$, considerándose en la actualidad como una cuestión que reviste la categoría de interés general por las repercusiones de distinta índole, que antes apuntábamos, supone -éticas, políticas, sociales-, y en especial, las que afectan a la órbita sanitaria. La intensa actividad normativa desplegada por el legislador tanto nacional como autonómico, en orden a intentar poner límites a este acuciante problema y el indiscutible interés doctrinal que despierta la materia ${ }^{13}$ es fiel reflejo de una preocupación que se prevé en progresivo aumento.

Por lo que respecta al concepto, su delimitación entraña cierta dificultad,

${ }^{12}$ Siguiendo a Ramos Gordillo, Antonio, Luch a contra el dopaje como objetivo de salud, cit. (n. 9), pp. 299-304, quien señala que el fenómeno del dopaje no es ni mucho menos de reciente aparición, más bien al contrario, "la historia del dopaje es tan antigua como la del mismo ser humano"; véase del mismo autor: El uso de sustancias para la mejora del resultado: de la mitología al fármaco, en Revista jurídica de deporte y entretenimiento: deportes, juegos de azar, entretenimiento y música, 11 (2004), p. 357. Así, el dopaje aparece en el deporte justo en los inicios del mismo, siendo no sólo conocido en la Grecia clásica, sino igualmente en la antigua Roma. "Tal es así que los atletas romanos intentaban mejorar, no sólo por medio del uso de las termas o de la gimnasia, sino también tomando drogas tonificantes, que incluso muchas veces eran nocivas. Pero no todo quedaba aquí, inclusive existía una lucha para que el contrincante recibiese alguna droga que le disminuyera su capacidad de rendimiento. Incluso los romanos en la época anterior a Jesucristo, drogaban a los caballos que competían en las carreras de cuadrigas, para que estos obtuvieran el mejor rendimiento. Estas pócimas se componían fundamentalmente de hidromiel, que como su nombre indica, es una solución acuosa de miel, de la que una vez fermentada, se aprovecha los efectos estimulantes del alcohol etílico que se producían al cabo de unos días de realizada la mezcla”.

${ }^{13}$ Obras de autoridades en materia de Derecho deportivo y particularmente en la especialidad de dopaje en el seno del deporte, son: Palomar Olmeda, Alberto, $E l$ dopaje en el deporte. Un intento de elaborar una visión sosegada y constructiva, Colección Derecho Deportivo, No 2 dirigida por Alberto Palomar Olmeda (Madrid, Dykinson, 2004); AA.VV., Régimen jurídico del dopaje en el deporte, en Millán GARRIDo, Antonio (coordinador), cit. (n. 13); AA.VV., Estudios sobre el dopaje en el deporte. Actas del Seminario celebrado en la Universidad Carlos III de Madrid (Campus Colmenarejo) durante el curso 2004-2005, en Asís Roig, Agustín de - Hernández SAN JuAn, Isabel (coordinadores), Colección Derecho Deportivo, No 8, dirigida por Alberto Palomar Olmeda (Madrid, Universidad Carlos III - Dykinson, 2006); AA.VV., Dopaje, fraude y abuso en el deporte, en Bosch CAPDEvila, Esteve - FrandUEt SUGRAÑES, María Teresa (coordinadores), Colección "Derecho y Deporte" dirigida por Antonio Millán Garrido (Barcelona, Bosch, 2007); AA.VV., Comentarios a la Ley Antidopaje en el Deporte, en Cazorla Prieto, Luis María - Palomar Olmeda, Alberto (directores), cit. (n. 9); Gomara Hernández, José Luis, “Doping”. El régimen jurídico del dopaje (Pamplona, DAPP Publicaciones Jurídicas, 2008); y, más recientemente, Gifford, C., Dopaje y deporte (traducción castellana de Manzano Bernárdez, Pablo, Colección ¿Y tú?, ¿qué opinas?, No 5, Madrid, Morata, 2010). 
ya que si bien efectivamente no es un fenómeno reciente, a pesar de ello, lo cierto es que aún no existe una definición universal de dopaje ${ }^{14}$ que haya sido unánimemente aceptada. Así las cosas, se nos antoja oportuno referirnos a la que se propuso en el Primer Coloquio Europeo de Medicina Deportiva, celebrado en el seno del Consejo de Europa en 1963: "Se considera dopaje la utilización de sustancias y medios que, destinados a incrementar artificialmente el rendimiento ante una competición, pudieran perjudicar la integridad física y psíquica del deportista".

Se trata de una definición que pone el acento en el daño que se ocasiona al individuo que practica una determinada actividad deportiva. Otras definiciones se centran en un aspecto legal en la medida en que sólo se reputará dopaje cuando se compruebe la presencia en el organismo del deportista de sustancias que aparecen recogidas en un listado incorporado en una norma de derecho positivo. Esta postura adoptó el Comité Olímpico Internacional (en adelante, COI), que en 1986 declaraba "la prohibición del uso en el deporte de métodos de dopaje y de clases de agentes dopantes incluidos en diversos grupos farmacológicos". Con un planteamiento de cariz semejante, el Convenio contra el Dopaje del Consejo de Europa, de 1989, establecía que "Se entenderá por dopaje en el deporte la administración a los deportistas o la utilización por éstos de clases farmacológicas de agentes de dopaje o de métodos de dopaje. Se entenderá por clases farmacológicas de agentes de dopaje o de métodos de dopaje...las clases de agentes de dopaje y de métodos de dopaje prohibidas por las organizaciones deportivas internacionales competentes y que figuren en las listas que hayan sido aprobadas por el Grupo de Seguimiento [...]"15.

${ }^{14}$ Véase Ramos Gordillo, Antonio. Un problema continuado y sin final: la definición de dopaje, en Revista jurídica de deporte y entretenimiento: deportes, juegos de azar, entretenimiento y música, 11 (2004), pp. 349-355. A este respecto, destaca el autor que actualmente no existe una única definición de dopaje que tenga validez universal para todos aquellos que luchan contra el mismo, a lo añade que esta problemática ocurre tanto en el ámbito institucional como en el ámbito de organizaciones o federaciones deportivas. Sobre el particular opina el autor que "si la definición existiese y fuese reconocida como universal, se daría un paso más en la lucha contra el dopaje" [Véase: Ramos Gordillo, Antonio, Lucha contra el dopaje como objetivo de salud, cit. (n. 9), pp. 300-301]. Análogamente, Dumas, P. Le doping (Paris, Gazette Médicale de France, 1977), pp. 7-12, reconoce que: "Todas las definiciones sobre el doping presentan lagunas y reflejan algunas divergencias: Una definición precisa no es absolutamente necesario establecerla a priori. Lo importante es comprender el problema. No podemos conformarnos con el concepto de los que se dopan y saben muy bien lo que buscan en semejante práctica: (Una mejor preparación, un mejor rendimiento, una recuperación más rápida) gracias a unos medios artificiales, más o menos eficaces y a veces peligrosos".

${ }^{15}$ Véase Malo De Molina, Diana, Medicina deportiva (jurídico), en Romeo 


\section{Las diferentes modalidades de dopaje y sus métodos.}

a) Administración de sustancias. Como venimos apuntando, el dopaje se refiere al uso de un artificio, bien una sustancia u otro método, que sea susceptible de mejorar el rendimiento de un deportista. Por tanto, una de las formas o medios empleados al efecto es precisamente la administración de sustancias.

En este plano, la creación de la Agencia Mundial Antidopaje ${ }^{16}$ (AMA en castellano, World Anti-Doping Agency, en inglés o WADA) ha supuesto un hito importantísimo en muchos aspectos, pero aquí cabe resaltar su labor de armonización de toda la normativa en cuanto a los controles de dopaje se refiere y en particular en su misión de unificación de la lista de sustancias no permitidas, pudiendo llegar a afirmarse que gracias a ella esta unificación prácticamente se ha logrado.

En España, corresponde desde 1990 al Consejo Superior de Deportes la elaboración y revisión periódicas de la lista de sustancias ${ }^{17}$, estando vigente el listado aprobado por Resolución de 10 de diciembre de 2012, que se

Casabona, Carlos María (director), Enciclopedia de Bioderecho y Bioética (Bilbao Granada, Cátedra Interuniversitaria de Derecho y Genoma Humano - Comares y el Instituto Roche, 2011), II, p. 1109-1110.

${ }^{16}$ Como señala Malo De Molina, Diana, Medicina deportiva (jurídico), cit. (n. 17), p. 1109, desde finales del siglo XX, tanto el COI como las Federaciones deportivas y un gran número de gobiernos de todo el mundo han buscado la armonización de las vías de lucha contra el dopaje. En aras de esta ansiada convergencia, en un ámbito caracterizado precisamente por la disparidad de normativas llevó a que en la Conferencia Mundial sobre el dopaje en el deporte, celebrada en Lausana durante los días 2 al 4 de febrero de 1999 bajo los auspicios del COI se crease la Agencia Mundial Antidopaje, integrada de forma paritaria por representantes de organizaciones deportivas, gubernamentales e intergubernamentales. El "Código Mundial Antidopaje" llegaría de la mano de la denominada "Declaración de Copenhague", adoptada el 5 de marzo de 2003 como culminación de la Conferencia Mundial sobre el dopaje en el deporte celebrada en esa misma ciudad [véase: Pérez González, Carmen - Rodríguez García, José, El contexto internacional de la ley, en Cazorla Prieto, Luis María - PALOMAR Olmeda, Alberto (directores), Comentarios a la Ley Antidopaje en el Deporte, cit. (n. 15), pp. 49-68.). Ahora bien, el principal problema que se suscitaba en este ámbito respondía al hecho de que el "Código Mundial Antidopaje" careciera de fuerza vinculante en el Derecho internacional público, por lo que un paso trascendental en este punto fue la aprobación de la Convención Internacional contra el Dopaje en el Deporte de la $U N E S C O$, en el sentido de que tras dicha aprobación se incorporan los principios del "Código Mundial" y esto hace posible la armonización de la normativa internacional sobre esta materia.

${ }^{17}$ A tenor de la Ley Orgánica $\mathrm{N}^{\circ} 7 / 2006$, en su artículo 12 se establece que, en el marco de la mencionada "Convención Antidopaje" de la UNESCO, el Consejo Superior de Deportes publicará en el Boletín Oficial del Estado, mediante resolución de su Presidencia, la lista de sustancias y métodos prohibidos en el deporte. 
publicó en el Boletín Oficial del Estado número 306, de 21 de diciembre de $2012^{18}$.

Si bien es cierto que la lista de sustancias y métodos prohibidos se encuentra actualmente armonizada, presenta los mismos hándicaps que en un inicio $\mathrm{y}$ es una fuente inagotable de problemas -y críticas doctrinales ${ }^{19}$ - desde el punto de vista médico y normativo.

Llegados a este punto es pertinente preguntarse por qué se incluye una determinada sustancia en la lista de sustancias no permitidas, esto es, cuáles son las razones de su inclusión. En principio y siguiendo al doctor Naranjo Orellana ${ }^{20}$ se obedece a tres argumentos. En primer lugar, porque la sustancia en cuestión tenga una clara acción ergogénica, lo que supone que resulte favorecedora del rendimiento físico, cuestión que implicaría una ventaja ilícita. En segundo lugar, la razón de ser respondería al hecho de que su utilización suponga un posible peligro para la salud del deportista. Y por último, un factor clave para que una determinada sustancia se incluya en la lista se debe a que ésta se utilice como medio para enmascarar o dificultar la detección de las sustancias dopantes en sentido estricto ${ }^{21}$.

En cuanto al primer argumento, la acción ergogénica, se refiere a la dimensión ética de la competición deportiva, al juego limpio -o tan sonado "fair play" al que aludíamos en un inicio-, a la lealtad y confianza para con el contrario. Pero este argumento es una "pendiente resbaladiza" cuando se circunscribe al mundo deportivo y especialmente si vinculamos deporteespectáculo, puesto que son ingentes los intereses comerciales y económicos que gravitan en este campo. A ello se suma que el concepto de la ética en el deporte es un concepto dinámico y en constante evolución. Si a estos vaivenes en torno a un dudoso sentido ético del deporte, en un mundo en el que parece que todo es "lícito" para el juego de esos intereses comerciales y económicos, le agregamos el hecho de que no todos los productos incluidos en la lista tienen acciones ergogénicas demostradas y aceptadas por toda la comunidad científica -como el cannabis, los anestésicos locales, los corticoides o los bronco-dilatadores a ciertas dosis- y que en cambio hay sustancias con acciones ergogénicas bastante reconocidas y de uso muy común -como

${ }^{18}$ Se puede consultar la Lista de Sustancias y Métodos Prohibidos prevista para 2013 en: http://www.boe.es/diario_boe/txt.php?id=BOE-A-2012-15381 [última consulta: 15 de marzo de 2013].

${ }^{19}$ Véase TAmburrini, C., ¿Qué tiene de malo el dopaje?, cit. (n. 9), pp. 45-71.

${ }^{20}$ Véase Naranjo Orellana, José, La lista, cit. (n. 13), pp. 181-192.

${ }^{21}$ Escribe con tino Naranjo Orellana, José, ibíd., p. 184, que a estas tres razones mencionadas ha de añadirse una cuarta, la "coherencia social", puesto que a su entender sólo esta razón justificaría la presencia de sustancias como la heroína, la metadona, la cocaína, el cannabis o el alcohol. 
es el caso de la creatina- que no están prohibidas, cabe concluir que, en términos generales, este argumento del juego limpio no resulta en absoluto sólido y sólo adquiere entidad en conexión con el segundo motivo, es decir, que represente un peligro para la salud del deportista ${ }^{22}$.

No obstante, este argumento del peligro para la salud, aun sustancialmente sólido, tampoco está exento de contradicciones ${ }^{23}$. Así, un gran número de las sustancias incluidas en la lista son fármacos de uso común que tienen un fin terapéutico convencional para la población general y que a las dosis habituales no suponen ningún efecto ergogénico revelador. Resulta alarmante que aún con todo, el deportista se ve privado del uso racional de estos fármacos y el médico ve "coartada" su labor como profesional. Podemos poner como ejemplo el caso de las sustancias broncodilatadoras utilizadas para el tratamiento del asma (técnicamente son broncodilatadores beta 2 adrenérgicos e incluyen al Salbutamol, Salmeterol, Formoterol y Terbutalina) ${ }^{24}$.

${ }^{22}$ Ibíd., p. 185.

${ }^{23}$ De esta contradicción se hace eco TAmburrini, C., ¿Qué tiene de malo el dopaje?", cit. (n. 9), pp. 46 ss., quien considera que el argumento de que el dopaje es nocivo para la salud de los atletas no es lo suficientemente sólido de cara a su prohibición. Este autor resalta que a su juicio la prohibición es arbitraria en relación a las sustancias que incluye. $Y$ desde esta perspectiva se pregunta que por qué ha de prohibirse el dopaje sanguíneo y la eritropoietina pero no el uso de carpas de alta presión. "Todos esos métodos producen el mejoramiento de la capacidad aeróbica del atleta mediante el aumento del número de hematocritos en su sangre. Correctamente aplicados, tampoco se diferencian en relación a los riesgos que conllevan para la salud de quien se somete a esos métodos de mejoramiento del rendimiento deportivo. Por otra parte, argumenta el autor que ciertas sustancias están prohibidas por algunas federaciones deportivas pero permitidas por otras. La efedrina (una substancia incluida en muchas medicinas contra el resfrío y la gripe) no está permitida en los reglamentos de la Federación Internacional de Fútbol Asociado (FIFA) pero sí en la American National Basketball Association (NBA).

${ }^{24}$ Siguiendo a Naranjo Orellana, José, La lista, cit. (n. 13), pp. 185, estas sustancias utilizadas en inhalación y a dosis terapéuticas no producen ninguna mejora en el rendimiento de un atleta; es más, ni siquiera ejercer su acción broncodilatadora sobre un bronquio que no esté previamente obstruido o sea especialmente vulnerable a la constricción (como es el caso del asma). Sin embargo, a determinadas dosis (por encima de 1.000 nanogramos por mililitro para el salbutamol), que nunca se alcanzarían por vía inhalatoria, tienen una acción anabolizante y esta situación está claramente diferenciada en la normativa de dopaje. Pues bien, el uso a dosis terapéuticas está tan restringido que el riesgo de positividad es alto, especialmente por defectos en el complejo mecanismo burocrático para su justificación, lo que limita seriamente su uso médico. Pero áun hay otro aspecto que afecta al uso de broncodilatadores por parte del deportista y es el diagnóstico. A los deportistas que utilicen estos fármacos se les exige que aporten una prueba positiva de hiperreactividad bronquial, entre las que se encuentra el test de metacolina que es un fármaco que administrado por vía inhalatoria en dosis 
Se trata de sustancias que utilizadas en inhalación y a dosis terapéuticas no producen ninguna mejora en el rendimiento del deportista. En efecto, las listas de sustancias presentan ejemplos de similares características, algunos de los cuales han desaparecido en las últimas revisiones (como es el caso de la codeína o de los anestésicos locales), otros desaparecieron a nivel internacional más pronto que en nuestro país (como la cafeína que finalmente ha dejado de engrosar la lista de sustancias prohibidas teniendo en cuenta sus dosis) y otros muchos permanecen (como es el caso de los broncodilatadores o los corticoides).

A ello se suma el problema que constituye la imprecisión de las listas al dejar los grupos abiertos, ya que a todos ellos les añaden al final de la redacción la expresión "a cualquier otra sustancia con acción análoga".

Por otra parte, se hace eco, entre otros, Naranjo Orellana de la gran preocupación por la salud de los deportistas que lleva "incluso a tutorizar los actos médicos, cuando el deporte de competición está rodeado de circunstancias que son un verdadero peligro para la salud y ante las que es frecuente mirar para otro lado"25. Generalmente la preocupación por la salud se limita al aumento de la relación de fármacos que el deportista no puede tomar, "aunque el resto de la población sí pueda hacerlo sin grandes riesgos para su salud".

Con todo, la combinación de los dos argumentos que hemos desarrollado tiene razón de ser respecto de un grupo de sustancias y métodos de dopaje que generan una clara ventaja para el que lo utiliza al tiempo que representan un grave riesgo para su salud. Es el caso de las hormonas peptídicas (especialmente la hormona del crecimiento), los anabolizantes, los antagonistas

crecientes provoca espasmo bronquial que reproduce la crisis de asma. Se considera que si esta reacción se produce con una dosis suficientemente baja de metacolina (menor de $25 \mathrm{mg} / \mathrm{Ml}$ ) es que existe una sensibilidad exagerada por parte del bronquio y, por tanto, se puede realizar el diagnóstico de asma. Pues bien, para los deportistas este test sólo se considera positivo si la reacción se produce con dosis de metacolina inferiores a $2 \mathrm{mg} / \mathrm{mL}$, lo que supone que sujetos que reaccionan por ejemplo con $5 \mathrm{mg} / \mathrm{mL}$ pueden considerarse asmáticos y ser tratados con salbutamol si no son deportistas, porque si lo son les está prohibido el tratamiento.

${ }^{25}$ Señala de forma muy expresiva Naranjo Orellana, esta paradoja: “a mí me gustaría, como profesional de la salud, que cuando un organismo (nacional o internacional) habla de que va a proteger la salud de los deportistas quisiera decir que las carreras ciclistas por etapas se van a reducir en su duración y trazados a límites compatibles con la naturaleza humana, o que se va a prohibir competir en la élite antes de la pubertad, o que se van a vigilar las tendencias anoréxicas fomentadas en algunas disciplinas deportivas, o que las carreras de resistencia se van a hacer en los horarios menos agresivos climatológicamente con independencia de lo que digan los intereses televisivos, o que se van a hacer obligatorios los exámenes médicos previos a la participación deportiva, o tantas otras cosas [...]”. 
estrogénicos o los métodos de dopaje sanguíneo (EPO y derivados, transfusiones, oxigenadores artificiales). Ahora bien el problema reside en que, en este campo de las sustancias efectivamente peligrosas y con resultados ergogénicos considerables parece que el que incumple siempre se adelanta y las listas y las normas dan generalmente una respuesta tardía. Así, hay situaciones previstas en la lista que en la práctica no son detectables por los métodos habituales (la propia EPO, si no se realizan controles sanguíneos) $\mathrm{u}$ otras que se encuentran en fase incipiente en términos científicos (como el caso del dopaje genético) que ya engrosan esa lista de sustancias/métodos prohibidos $^{26}$, pero se produce la paradoja de que hay sustancias que aún descubiertas y consolidadas en su uso tardan en incluirse en las listas.

Abundando en el sano criterio del autor mencionado, hemos de afirmar que los baremos de positividad en algunas de las sustancias mencionadas resultan lo suficientemente ambiguos como para que con frecuencia salten a la luz mediática casos que se demoran en su resolución y que no contribuyen en absoluto a la credibilidad de la lucha contra el dopaje, generando reacciones críticas o incluso una visión generalizada del Derecho como instrumento ineficaz de protección de bienes jurídicos (algo similar ha sucedido con el archivo de la conocida como "Operación Galgo" que envolvía a la atleta Marta Domínguez, y a un sinfín de profesionales sanitarios y entrenadores.)

b) Otros métodos o técnicas de dopaje. Existen junto a las sustancias otros métodos o técnicas de dopaje, como el "dopaje sanguíneo" o el controvertido "dopaje genético", que se postula como protagonista en un escenario deportivo con un horizonte no muy lejano ${ }^{27}$. Respecto de este último, la propia Agencia Mundial Antidopaje, adelantándose a esta inminente realidad, incluyó esta técnica ya en 2003, fruto de la emblemática Conferencia de Banbury - celebrada en Nueva York en 2002- que versó en exclusiva en torno a esta problemática. Actualmente la Lista de sustancias y métodos prohibidos prevista para el 2013 refiere al dopaje genético: "Lo siguiente, con el potencial de mejorar el rendimiento deportivo, está prohibido: 1- La transferencia de polímeros de ácidos nucleicos o análogos de ácidos nucleicos; 2- El uso de células normales o genéticamente modificadas", excluyéndolo expresamente como método prohibido. En concreto, los genes que se encuentran vinculados al rendimiento físico y por ende, adquieren re-

\footnotetext{
${ }^{26}$ Consulta de la lista de sustancias y métodos prohibidos para 2013 en la página de la Agencia Mundial Antidopaje - WADA: http://list.wada-ama.org/es/prohibited-incompetition/prohibited-substances/ [última consulta: 15 de marzo de 2013].

${ }^{27}$ Interesantes reflexiones en torno al dopaje genético -en el contexto de los desarrollos tecnológicos en favor del mejoramiento físico- en PÉreZ Triviño, José Luis, The Challenges of Modern Sport to Ethics From Doping to Cyborgs (New York, Lexington Books, 2013).
} 
percusión en el ámbito deportivo, serían: Eritropoyetina (EPO) el factor-1 de crecimiento insulina, la hormona del crecimiento, los factores de inducción hypoxia y los receptores de activación de los proliferadores de los peroxismas. Esta nueva institución entendemos que se ha de circunscribir al ámbito de las intervenciones (o más propiamente manipulaciones) genéticas en el ser humano con finalidad de mejoramiento (englobadas dentro del concepto tan en boga últimamente del human enhancement). Difieren, por tanto de la llamada "terapia génica" que si bien a su vez se engloba en el seno de las manipulaciones genéticas persigue en este caso la curación de enfermedades -denotan un fin terapéutico o reparador-. En el caso del "dopaje genético" partimos, en cambio, de un estado de "normalidad" del atleta y se pretende un logro de records que ha de superar obviamente la normalidad. Esta distinción con la terapia génica es un matiz que es muy importante traer a colación porque es bastante frecuente en la literatura incluso científica que versa sobre el dopaje genético que ambos conceptos "terapia génica" y "mejora genética" se diluyan o no queden meridianamente diferenciados.

\section{Efectos secundarios del dopaje.}

a) Efectos físicos y psíquicos. El abordaje o tratamiento de los efectos que para la salud suponen las conductas de dopaje en el deporte es una prioridad a nivel de la Unión Europea ${ }^{28}$-espacio que es más conocida o afín a nosotros-, y por supuesto, en la esfera mundial. Así las cosas, los recientes y alarmantes sucesos deportivos internacionales constituyen un recordatorio de la necesidad de mantener la cuestión del dopaje viva.

A pesar de que los controles antidopaje, los análisis de laboratorio y actividades de esta índole se han ido ampliando y desarrollando, existe aún hoy una falta de conocimiento, una anemia, sobre los efectos secundarios

${ }^{28} \mathrm{Si}$ bien es cierto que, por una parte, el Tratado de la Unión Europea no fija unas específicas bases jurídicas o fundamento jurídico específico en lo referente a la lucha contra el dopaje en el deporte, en el campo de la salud pública, por otra, la Unión Europea ha suplido esta carencia y ha tomado medidas para complementar las actividades de los Estados miembros dirigidas a reducir los daños para la salud que pueden causar las sustancias dopantes, entre estas acciones se incluyen la información y la prevención. Así, en 1999, la Comisión adoptó un plan de apoyo comunitario para luchar contra el dopaje en el ámbito del deporte. Como reflejo de este propósito destaca el proyecto que la Unión Europea encomendó a la Technische Universität München (TUM) en torno a los efectos biomédicos secundarios del dopaje, bajo el título: "Harmonising the knowledge about biomedical side effects of doping" en el contexto del Programa de Salud Pública 2003-2008. Se pueden seguir las implicaciones del proyecto y logros en la página web creada al efecto: http://www.doping-prevention.com/ [última consulta: 15 de marzo de 2013]. 
en el horizonte biomédico del dopaje, siendo un asunto pendiente entre el público en general, los atletas y el mundo del deporte.

Un mayor conocimiento de los efectos, inmediatos y a largo plazo, a nivel físico y psíquico del dopaje resulta esencial entre los entrenadores y deportistas, en particular entre los jóvenes deportistas con el fin de que resistan la tentación del dopaje. La combinación de sustancias lícitas e ilícitas en el dopaje lleva a efectos en la salud complejos, que son difíciles de manejar, especialmente en la adolescencia, que encabezan un grupo de riesgo de especial consideración.

La medicina contemporánea, la fisiología, la bioquímica, la genética y la farmacología traen consigo infinitas posibilidades en orden al mejoramiento del rendimiento en el ámbito deportivo. A pesar de que los fármacos -que desde algún aspecto podrían denominarse “drogas”-, están principalmente designados para curar a las personas que sufren de diferentes enfermedades, es decir, tienen finalidad predominantemente curativa ${ }^{29}$, éstos son también objeto de un mal uso por deportistas sanos para conseguir una ventaja adi-

${ }^{29}$ En el estadio en que nos encontramos ha de hacerse notar la particularidad de la Medicina del Deporte, una especialidad en la que claramente convergen las facetas curativa y no curativa de la práctica profesional. Siguiendo a TERRADOs CEPEDA, Nicolás, La salud de los deportistas desde la perspectiva del médico de equipo, en Asís Roig, Agustín de - Hernández San Juan, Isabel (coordinadores.), cit. (n. 15), pp. 143 ss., señala que desde la perspectiva de actividad orientada al cuidado de la salud y el restablecimiento de procesos patológicos, "resulta plenamente incluida dentro de la denominada medicina curativa", ahora bien subraya este autor que desde el punto de vista de esta medicina como protectora de un desgaste prematuro y de establecimiento de un entrenamiento que favorezca las funciones orgánicas, enfocado a la longevidad o a la competición, es una práctica que se puede incardinar dentro de la medicina no curativa o satisfactiva a la que el paciente acude buscando la mejora de un aspecto físico, psicológico o estético. Por ello, afirma que cuando un médico especialista en Medina del Deporte trata a un enfermo, tiene las mismas obligaciones o deberes que se le corresponden a cualquier facultativo dentro de una obligación de medios y además, "cuando colabora en la preparación de deportista, adquiere una dimensión en la que se produce un reforzamiento del deber de informar al paciente, de los riesgos de las terapias propuestas así como de la posibilidad de que éstas no proporcionen los resultados apetecidos y de los cuidados, actividades y prácticas que resulten precisas para asegurar el éxito del tratamiento". De esta forma, concurrirían diferentes modelos de atención médica en el contexto de la Medicina del Deporte. Así, atendiendo al tipo de actividad destacamos el deporte orientado al rendimiento y el deporte enfocado en la salud. Resalta Terrados Cepeda que "mientras que en ambos tipos de actividad física la atención médica conlleva la responsabilidad por la propia atención médica”, en el deporte de competición, es decir orientado al rendimiento, la responsabilidad puede ampliarse con ocasión de la normativa del dopaje. Véase también: Malo De Molina, Diana, Medicina deportiva (jurídico), cit. (n. 17), p. 1109-1110. 
cional sobre otros competidores a pesar de los posibles efectos secundarios negativos a corta y larga duración que pueden acarrearles.

Al hilo de lo antes dicho, los efectos secundarios del dopaje se refieren a la esfera física -desde el sistema cardiovascular, sistema gastrointestinal, al sistema reproductor y endocrino, al sistema inmune, e igualmente algunas sustancias dopantes pueden ejercer efectos secundarios peligrosos para la vida sobre el sistema respiratorio de los atletas, otros órganos pueden verse afectados como es el caso del riñón, hígado, entre otros-, así como a la psíquica ${ }^{30}$, esto es, efectos psicológicos y adicciones, que se traducen en numerosas ocasiones en enfermedades o trastornos mentales, efectos que a tenor de algunos casos reales afectan incluso a la descendencia del propio deportista. De esta forma, deportistas que utilicen o lo hicieran en su período de deportistas en activo sustancias dopantes que con la finalidad de mejorar la destreza deportiva, pueda causar mutaciones del $\mathrm{ADN}$ y por lo tanto dar lugar a que los hijos nazcan con discapacidades de esta índole. No en vano existen casos $^{31}$ de hijos con trastornos mentales como es el caso de la epilepsia.

b) Incidencia mediática de la cuestión. Referencia de algunos casos renombrados. Un supuesto que entronca con lo anteriormente mencionado y que ha puesto sobre la palestra el tema del dopaje deportivo y la adicción, es el del nadador Michael Phelps, ante la sospecha de su adicción, concretamente a la marihuana. Su caso adquirió relevancia internacional debido a que el nadador se convirtió en uno de los deportistas más publicitados y millonarios de la historia tras romper el récord de 8 medallas de oro olímpicas en Beijing 2008 y que sus representantes y patrocinadores tuvieron la intención de censurar las fotografías para defender sus intereses económicos ${ }^{32}$.

Otro caso notorio es el de Florence Griffith Joyner que, de forma sorpresiva, el 21 de septiembre de 1998 y con tan sólo 38 años, moría víctima

${ }^{30}$ Un caso extremo es que acaeció un 15 de septiembre de 1973: el danés Kaj ANDERSEN (Viborg, 4 noviembre 1943) lanzador de disco, se suicidaba tirándose desde la torre de la Catedral de Viborg, un año después de su fracaso en los Juegos Olímpicos de Munich. Anteriormente, había sido ingresado en un hospital psiquiátrico puesto que el consumo de esteroides anabólicos había afectado a su estabilidad psíquica, generándole conductas agresivas (datos extraídos de la Komisja Do Zwalczania Dopingu W Sporcie en colaboración con la WADA).

${ }^{31}$ Véase la noticia en prensa en: http://mexico.cnn.com/deportes/2012/01/29/ ninos-afectados-jugadores-de-argelia-buscan-respuesta-a-dopaje [última consulta: 15 de marzo de 2013].

${ }^{32}$ Algunos periódicos de mayor repercusión se hacían eco de esta noticia, por ejemplo The New York Times (5 febrero de 2009), disponible en: http://www.nytimes. com/2009/02/06/sports/othersports/06phelps.html [última consulta: 15 de marzo de 2013]. 
de una apoplejía cerebral ${ }^{33}$. Su temprana muerte reactivó la polémica en torno a las causas que la habían provocado, posiblemente relacionadas con los productos consumidos en su etapa como atleta.

Sucesos como los que hemos ilustrado tuvieron en su día un fuerte impacto en los medios de comunicación, y en un gran número de ocasiones estuvieron fundados en puras sospechas circunstancia que nos empuja a cuestionarnos la posible vulneración del derecho a la intimidad de los deportistas en cuestión.

\section{EL DERECHO A LA INTIMIDAD Y LA PROTECCIÓN DE LA SALUD}

\section{Controles antidopaje y deber de localización permanente.}

a) Sobre los controles: razón de ser, evolución y organismos creados ad hoc. Una vez que hemos puesto de relieve las consecuencias tan perniciosas que para la salud, tanto física como psíquica, generan estas conductas de dopaje (ya sea vía sustancias/productos dopantes o valiéndose de otros métodos) es lógico llegar al indiscutible convencimiento de que se debe proteger la salud del deportista contra la que estas prácticas atentan -o de forma previsible pueden atentar- incluso muy gravemente, y como hemos visto en líneas anteriores, con efectos irreversibles que pueden llegar a ser fatales.

Quedando de forma palmaria evidenciada la protección de la salud como el eje sobre el que pivota la política antidopaje en el deporte, los controles y actividades que se establezcan deben estar destinados a mejorar, controlar y prevenir los efectos contrarios a la salud que pueda producir la actividad deportiva. Con este propósito se manifiesta la Ley Orgánica de Protección de la Saludy de Luch a contra el Dopaje en el Deporte -Ley Orgánica N 7/2006, de 21 de noviembre, piedra angular, como hemos mencionado, de la lucha antidopaje a nivel español ${ }^{34}$-, en concreto en su artículo 8.2. Y es que esta

${ }^{33}$ Se puede revisar la hemeroteca de periódicos como El País que reflejaban la noticia (24 de septiembre de 1998), disponible en: http://elpais.com/diario/1998/09/24/ deportes/906588006_850215.html [última consulta: 15 de marzo de 2013].

${ }^{34} \mathrm{~A}$ fecha de cierre de este trabajo, el Consejo de Ministros - a propuesta del Ministro de Educación, Cultura y Deportes, José Ignacio WERT-, aprobaba en su reunión de 8 de marzo de 2013 la remisión a las Cortes Generales del Proyecto de Ley Orgánica de Protección de la Salud del Deportista y de Lucha contra el Dopaje en la Actividad Deportiva, publicándose en el Boletín Oficial de las Cortes Generales (BOCG) con fecha de 15 de marzo de 2013. Esta nueva normativa -como se desprende de la propia Exposición de Motivos del proyecto de ley orgánica- recoge una serie de medidas encaminadas al total cumplimiento de los compromisos que España ha asumido en el plano internacional en materia de dopaje y en especial a la adaptación plena con respecto a la normativa que lidera de forma indiscutible este ámbito, esto es, el Código Mundial Antidopaje. 
lucha se entabla mediante el establecimiento y desarrollo de acciones no sólo preventivas sino también represivas, cuyas miras son, por un lado convencer al deportista de que tiene la posibilidad de competir y ganar sin recurrir al dopaje, buscando, en definitiva, una disuasión de estas prácticas, y por otra basándose en las consecuencias de sus actos. De esta forma, y siendo incuestionable que la prevención es factor clave para tratar de erradicar el dopaje, o por lo menos disminuir su práctica, difícilmente se puede negar que el control sea la acción imprescindible para llegar a alcanzar, o por lo menos aproximarse, a los designios de esta "cruzada" en contra del dopaje.

Siguiendo esta tónica generalizada, no es de extrañar que en el texto de la Ley Orgánica $N^{\circ} 7 / 2006$, la referencia a los controles de dopaje ${ }^{35}$ constituya una constante, complementada con las disposiciones relativas a los controles y demás actividades de protección de la salud. La normativa en este ámbito se fundamenta en las competencias de la Administración General del Estado y en el ejercicio de las correspondientes funciones que en dicha normativa se determina ejercerán los organismos siguientes creados al efecto: El Consejo Superior de Deportes, la Comisión de Control y Seguimiento de la Salud y el Dopaje y la Agencia Estatal Antidopaje.

Pero ¿qué se entiende por control antidopaje? En la propia Ley Orgánica $7 / 2006$ se definen los controles, de forma armonizada con las definiciones que los textos internacionales adoptan al respecto. Así y de acuerdo con la AMA, un control antidopaje es el proceso que incluye la planificación de controles, la recogida y manipulado de muestras, los análisis de laboratorio, la gestión de los resultados, las vistas y las apelaciones. En conexión con esto, la propia ley antidopaje española, se refiere a las actividades de control "antidoping" como el conjunto de los siguientes procedimientos: i) La planificación de los controles antidopaje y la selección de los deportistas a controlar; ii) La recogida, el manipulado y el transporte de las muestras del control antidopaje; iii) Los procedimientos analíticos y complementarios de laboratorios realizados a las muestras del control antidopaje; $\mathrm{y} i v$ ) La gestión de los resultados analíticos.

Por tanto, España se encuentra ante un período de cambio legislativo relevante que entraña un nuevo escenario normativo que supondrá la derogación de la actual normativa reguladora del dopaje, esto es, la vigente Ley Orgánica 7/2006, de 21 de noviembre, de Protección de la Salud y de Lucha contra el Dopaje en el Deporte y la aprobación de una nueva Ley Orgánica, ley que excede con mucho de lo que sería una simple norma antidopaje, siendo la intención del legislador la inclusión de un potente sistema de protección integral de la salud para quienes realicen cualquier actividad deportiva.

${ }^{35}$ Véanse más ampliamente sobre los controles antidopaje: Rodríguez Bueno, Cecilia, De los controles y la responsabilidad de su realización", en Cazorla Prieto, Luis María - Palomar Olmeda, Alberto (directores), Comentarios a la Ley Antidopaje en el Deporte, cit. (n. 15), pp. 185 y ss. 
En lo que a nuestro estudio respecta, hemos de centrarnos en la actividad de planificación, habida cuenta las repercusiones que supone en el derecho a la intimidad y por tratarse de una función trascendental en la medida en que de ella va a depender que se puedan alcanzar los fines disuasorios que la práctica del dopaje persigue con la realización de sus controles.

Así, la función de planificación -encomendada a la Comisión de Control y Seguimiento de la Salud y el Dopaje-, ha de llevarse a cabo mediante la necesaria ponderación en su distribución entre los llamados "controles en competición" y "controles fuera de competición" (que han generado una gran controversia como veremos), teniendo en cuenta que, aunque el mayor efecto disuasorio se alcanza realizando controles fuera de competición, es decir sin preaviso, obviamente se han de mantener los controles en competición, encaminados en su mayor parte a clasificaciones u obtención de récords. Paralelamente han de programarse controles aleatorios, tanto en competición como fuera de ella, en aras del mencionado efecto disuasorio; siendo ineludible que la planificación contemple un significativo porcentaje de controles a realizar a deportistas específicos o a grupos de deportistas, seleccionados sobre una base no aleatoria, para realizar un control en una determinada ocasión, por circunstancias específicas, ya sean previstas o imprevistas ${ }^{36}$.

Resulta fundamental que en la elaboración de los planes individualizados, se tome en consideración el estatus del deportista, en la medida en que si éste ostenta un carácter internacional puede también ser controlado en competiciones de este rango por su correspondiente federación internacional, pudiéndose originar una repetición de controles al mismo deportista en un plazo muy corto de tiempo; e incluso en ocasiones se podrían ejecutar controles simultáneos, bajo la responsabilidad de diferentes organizaciones antidopaje. Así, resulta obvio que la duplicidad de controles, en la mayoría de los casos, no es práctica recomendable, salvo en ocasiones muy específicas, por lo que el conocimiento bilateral de las actuaciones nacionales e internacionales resulta capital.

Una iniciativa decisiva en este sentido ha sido la creación de un banco de datos internacional bajo la premisa de la lucha contra el dopaje. Este proyecto, que se planteó en 2009 con el nuevo "Código Mundial Antidopaje", trae consigo una serie de implicaciones de gran calado para la protección de la intimidad personal del deportista, que se acrecientan en base al elemento de notoriedad y relevancia social que suele acompañar si hablamos de conocidos personajes del mundo del deporte. Nos referimos a la Base ADAMS ${ }^{37}$

${ }^{36}$ De nuevo Rodríguez Bueno, Cecilia, De los controles y la responsabilidad de su realización, en Cazorla Prieto, Luis María - Palomar Olmeda, Alberto (directores), Comentarios a la Ley Antidopaje en el Deporte. cit. (n. 15), pp. 190 ss.

${ }^{37}$ Véase el funcionamiento y desarrollo del Programa ADAMS en la sección 
(“Anti-Doping Administration \& Management System”), que supone una herramienta cardinal en cuanto a coordinación se refiere -utilizable por las organizaciones antidopaje-, por cuanto recoge los datos necesarios de los deportistas susceptibles de ser controlados, debiendo quedar en ella perfectamente delimitados los que pueden participar en competiciones internacionales y los que sólo compiten a nivel estatal, evitando esa indeseable duplicidad de controles que advertíamos más arriba.

Entre los datos que en su caso han de introducirse para sustentar esta base, con el más absoluto respeto a los principios de la vigente Ley Orgánica $\mathrm{N}^{\circ} 15 / 1999$ de protección de datos de carácter personal, se encuentran como prioritarios los referentes a un aspecto sustancial para nuestro estudio, esto es, la localización de los deportistas ${ }^{38}$ (paradero del deportista o "whereabouts") que legalmente pueden ser sometidos a un control de dopaje. Se trata de una función que es crucial para maximizar ese efecto sorpresa que anteriormente planteábamos y, en consecuencia, la eficiencia de los controles fuera de competición sin previo aviso.

Su introducción, modificación y consulta, con una delimitación exquisita de las posibilidades de acceso restringido, constituyen aspectos que se establecen según los requerimientos internacionales, y respetando los derechos

creada al efecto por la Agencia Mundial Antidopaje: http://www.wada-ama.org/en/ ADAMS/ [última consulta: 15 de marzo de 2013].

${ }^{38}$ Véase Molina Navarrete, Cristóbal, Nadal contra los "Vampiros" de la AMA: la luch a por el derecho a la intimidad en la relación deportiva profesional (Monografía Asociada a la Revista Aranzadi de Derecho de Deporte y Entretenimiento, No 5, Pamplona, Aranzadi, 2010); y del mismo autor Nadal lleva razón, la AMA se extralimita en su control antidopaje: el derecho a la intimidad del deporte profesional autónomo, en Revista jurídica de deporte y entretenimiento: deportes, juegos de azar, entretenimiento y música, 26 (2009), pp. 43-64. El autor en un tono muy expresivo y clarificador describe los avatares y circunstancias que rodearon a la problemática de la localización permanente de los deportistas que desembocó a nivel jurídico en la modificación del Real Decreto $\mathrm{N}^{\circ} 641 / 2009$, de 17 de abril, que regula los procesos de control de dopaje y los laboratorios de análisis autorizados para adecuarlo al "Código Mundial Antidopaje”, mediante el Real Decreto $\mathrm{N}^{\circ} 1462 / 2009$. De tal manera que en concordancia con dicho código, los deportistas han de comunicar, con tres meses de antelación, dónde están localizables durante una hora, entre las 06.00 y las 23.00 horas, todos los días y durante todo el año, para someterse a posibles controles.

Sobre el particular hemos de apuntar que entre las novedades que planteará la mencionada Ley orgánica de protección de la salud del deportista y de lucha contra el dopaje en la actividad deportiva -actualmente en fase de tramitación parlamentaria- destaca el hecho de que no se podrán efectuar controles antidopaje entre las 23.00 horas y las 6.00 horas, salvo en casos excepcionales, que deberán estar motivados y ser explicados al deportista. De tal manera que si no se sigue este procedimiento, el afectado podría recurrir a los tribunales por no haber sido informado. 
(en esta órbita destaca el derecho a la intimidad) y obligaciones que tienen los deportistas y las organizaciones antidopaje en relación a esta cuestión, así como bajo los condicionantes legales en cuyo marco se han de adoptar, desarrollar y supervisar.

b) El deber de localización permanente. ¿Justifica su obligatoriedad la protección de la salud individual y la salud pública? Con estos antecedentes podemos afirmar que la lucha contra el dopaje en el terreno deportivo está fundándose $-\mathrm{y}$ cada vez con mayor intensidad y conflictividad-, en la realización a los deportistas por parte de las organizaciones antidopaje de controles "antidoping" especialmente fuera de competición, siendo imperante en este sentido poder localizar al deportista. Bajo esta premisa, algunas organizaciones están exigiendo, por ende, la localización permanente de estos atletas. Ahora bien, nos plantearnos en este punto, si puede justificarse la obligación de localización de los deportistas y, por lo tanto, la intromisión en su intimidad para proteger un asunto que ha centrado nuestro trabajo, esto es, la salud. De este modo, valoraremos la cuestión desde el prisma de la salud individual y de salud pública.

Así las cosas, se nos antoja fundamental partir del Convenio para la protección de los derechos humanos y la dignidad del ser humano con respecto a las aplicaciones de la Biología y la Medicina (Convenio relativo a los derechos humanos y la biomedicina), hecho en Oviedo el 4 de abril de $1997^{39}$, el cual detalla en su artículo 10 que "Toda persona tendrá derecho a que se respete su vida privada cuando se trate de informaciones relativas a su salud". Así, exige que todas las acciones se desarrollen con pleno respeto por los derechos fundamentales de las personas y, entre ellos, el respeto por la intimidad.

En primer lugar, con respecto a la salud individual de los deportistas, hemos de matizar que si bien la protección de la salud está regulada en el artículo 43 de la Constitución Española -y, por lo tanto, no está considerada como un derecho fundamental-, atendiendo al decisivo papel de la salud en relación con la protección de la persona y su dignidad, el Tribunal Constitucional ha vinculado la salud con otros derechos, como la integridad física para, de facto, dotarla de rango de derecho fundamental ${ }^{40}$. A resultas

\footnotetext{
${ }^{39}$ Establece en su artículo 1 que: "Las Partes en el presente Convenio protegerán al ser bumano en su dignidad y su identidad y garantizarán a toda persona, sin discriminación alguna, el respeto a su integridad y a sus demás derechos y libertades fundamentales con respecto a las aplicaciones de la biología y la medicina".

${ }^{40}$ La sentencia del Tribunal Constitucional 35/1996, de 11 de marzo, afirmó que: "también el derecho a la salud, o mejor aún, a que no se dañe o perjudique la salud personal, queda comprendido en el derecho a la integridad personal". Interesantes reflexiones sobre este asunto en Rodríguez García, José, El deber de localización de los deportistas y su derecho a la intimidad: especial referencia al consentimiento, en Revista jurí-
} 
de ello, nos encontramos en una situación de ponderación de dos derechos fundamentales: por un lado, el derecho a la intimidad y por otro, el derecho a la salud. Ahora bien hemos de subrayar en este ámbito que se trata de derechos que tienen el mismo sujeto activo, esto es, el deportista sometido a la obligación de estar permanentemente localizado. Así, no parece atinada la ponderación entre dos derechos fundamentales que pertenecen a la misma persona. $Y$ es que en este punto resulta fundamental el consentimiento de interesado, en la medida en que lo que se trata es de proteger su propia salud, la salud individual -posición distinta supone si es la salud pública lo que está en juego, como veremos más adelante- ya que de no observar su voluntad, expresada mediante dicho consentimiento, nos situaríamos en una tendencia paternalista, superada ya en nuestros tiempos.

Redundando en esta idea, el Tribunal Constitucional en la sentencia 154/2002, de 18 de julio, afirmó que "cobra especial interés el hecho de que, al oponerse el menor a la injerencia ajen a sobre su propio cuerpo, estaba ejercitando un derecho de autodeterminación que tiene por objeto el propio sustrato corporal -como distinto del derecho a la salud o a la vida-y que se traduce en el marco constitucional como un derecho fundamental a la integridad fisica (art. $15 C E)$ ".

Por consiguiente y a tenor de la doctrina del Tribunal Constitucional ${ }^{41}$, hemos de concluir que para que pueda producirse la intromisión en los derechos fundamentales de los deportistas, derivada de la obligación de localización permanente, con el objeto de preservar la salud individual de éstos, su consentimiento resulta vital.

No obstante, se hace necesario destacar que con respecto a la voluntariedad del individuo están previstas, en la esfera sanitaria, determinadas excepciones derivadas de la irrenunciable protección de la salud pública. Este planteamiento se enlaza con el dopaje puesto que éste adquiere -como parece desprenderse de la "Exposición de motivos" de la Ley Orgánica $\mathrm{N}^{\circ}$ 7/2006- la categoría de problema de salud pública, porque afecta "tanto a los deportistas profesionales como a los practicantes habituales u ocasionales de alguna actividad deportiva", así "como a la práctica deportiva de base que, con carácter recreativo y saludable, desarrollan en nuestro paismillones depersonas".

dica de deporte y entretenimiento: deportes, juegos de azar, entretenimiento y música, 31 (2011), pp. 181-248.

${ }^{41}$ Así, la jurisprudencia del Tribunal Constitucional, por todas su sentencia 120/1990, de 27 de junio, al referirse a la afección en la integridad física y moral del individuo en relación con la salud de las personas, ha dicho que la integridad física y moral "protege la inviolabilidad de la persona, no sólo contra ataques dirigidos a lesionar su cuerpo o espiritu, sino también contra toda clase de intervención en esos bienes que carezca del consentimiento de su titular". 
En España el legislador se ha decantado por preservar la salud pública en el ámbito de la lucha contra el dopaje, tipificando determinadas acciones con la introducción de un "relativamente nuevo" artículo 361 bis en el Código Penal, a través de la propia Ley Orgánica $\mathrm{N}^{\circ} 7 / 2006$, dentro precisamente de los delitos contra la salud pública. Este delito persigue la protección de la salud de cualquier persona que practique un deporte, bien en práctica competitiva o bien de forma recreacional, de tal manera que "cualquier restricción de los sujetos pasivos de la infracción hubiera resultado incoherente, ya que la actividad deportiva debe ponerse al alcance de todas las personas, respetando las aspiraciones y capacidades de cada uno y con toda la diversidad de prácticas competitivas o de ocio, organizadas o individuales" ${ }^{\prime 2}$.

Una vez sentada la constitucionalidad del bien "salud pública", no podemos dejar de ignorar la colisión existente entre ese bien y el derecho fundamental de los deportistas a su intimidad, que reclama una solución de forma inexcusable. La ponderación entre el derecho a la intimidad de los deportistas sometidos a la obligación de localización permanente y la preservación de la salud pública ha de iniciarse valorando la relevancia de la intervención en el derecho fundamental y la del fin perseguido, siendo en este caso la salvaguardia de la salud pública.

Respecto a este punto, cierta doctrina ${ }^{43}$ entiende que la incidencia en el derecho a la intimidad de los deportistas, como consecuencia de la obligación de localización permanente, es de una magnitud tal, que implica que debe considerarse violado el contenido esencial del derecho; y frente a ello, la salud pública, si bien es incuestionable como objetivo relevante, parece que no se puede considerar muy mejorada con esta obligación de localización, por una serie de razones:

Por un lado, la protección de la salud pública implica o trasciende a la protección de cualquier persona que practique un deporte bien de forma competitiva o recreacional. De tal forma que la salud pública se vería mejorada si la lucha contra el dopaje alcanzase a todos los practicantes de la actividad deportiva, sea de manera habitual u ocasional. Vemos que en la realidad esto no sucede así puesto que los controles de dopaje se están efectuando, salvo algunas excepciones, solo a los deportistas profesionales de élite o de alto nivel; y de estos deportistas un número realmente reducido es sancionado por dopaje.

Pero por otro lado, la obligación de facilitar todos los datos precisos que permitan la localización de los deportistas no conlleva que se pongan en

${ }^{42}$ Cortés Bechiarelli, Emilio, El delito de dopaje (Valencia, Tirant lo Blanch, 2007), p. 65.

${ }^{43}$ Más ampliamente Rodríguez García, José, El deber de localización, cit. (n. 42), pp. 181-248. 
marcha medidas concretas y serias para mejorar la salud pública, en este caso reflejadas en controles antidopaje, sino tan sólo significa que esos controles podrían llegar a realizarse, pero no que efectivamente se estén realizando.

Concluimos acorde con esta doctrina que la incidencia positiva en la salud pública que supone la obligación de localización de los deportistas es muy escasa. Especialmente de la ponderación de ambos valores en juego se extrae que el sacrificio del derecho a la intimidad de los deportistas es muy alto y, frente a ello, el beneficio que adquiere la salud pública derivado de tal sacrificio es muy bajo ${ }^{44}$. Por lo tanto, podríamos afirmar con prudencia que debe prevalecer, este caso y con las actuales condiciones, el derecho a la intimidad de los deportistas sobre la salud pública, por lo que la obligación que les es impuesta de facilitar a las organizaciones antidopaje los datos que permitan localización permanente no supera el juicio de proporcionalidad en sentido estricto ${ }^{45}$.

\section{CONSIDERACIONES FINALES}

Se nos antoja concluir este trabajo con unas palabras del célebre tenista español Rafael Nadal, quien resumía, de forma muy expresiva, el asunto tratado en líneas precedentes con estas palabras: "Si fueran cuatro competiciones al año, vale; pero en nuestro deporte, si ni mi tío ni mi madre saben dónde estoy. Que yo tenga que mandar un mensaje o estar asustado porque tenga que hacer un cambio un día, porque a las tres veces que no estés a esa hora te sancionan directamente como dopaje. Me parece una falta de intimidad tremenda $[\ldots]^{\prime \prime 4}$.

${ }^{44}$ Ibíd., pp. 181-248.

${ }^{45}$ Sobre este extremo se ha pronunciado Molina Navarrete, Cristóbal, Nadal contra los "Vampiros", cit. (n. 39) y de forma muy contundente: "la legitimidad de eventuales controles fuera de competición y por sorpresa, por tanto en un ámbito extralaboral, debe siempre conciliarse con el respeto del derecho fundamental a una vida privada controlada por el deportista en una parte suficiente para que el derecho sea reconocido en nuestra cultura. Por lo tanto, siempre es necesario mantener, aun aceptando limitaciones adicionales por el marco organizativo, institucional y contractual específicos del deporte y la fuerza del imperativo del juego limpio, el juicio de proporcionalidad, que no se compadece nada con una política de control casi obsesiva y típica de una modo de pensar basado en la sospecha del juego sucio por la búsqueda egoísta del puro rendimiento deportivo. A mi juicio, la regulación [...] no es proporcionada [...] Por eso, la aplicación del rígido e invasor, para la esfera personal del deportista, régimen de disponibilidad, localización e información del artículo 11 del referido estándar no ha de superar, en su aplicación en territorio español, el escrutinio o juicio propio de legitimidad constitucional".

${ }^{46}$ Declaraciones del célebre tenista para el periódico deportivo Marca, el 28 de enero de 2009, sobre la enorme polémica generada a raíz de la exigencia del Código 
Con todo, si bien es loable la lucha contra el dopaje como postura encaminada, en particular, a la protección de la salud de los deportistas, las medidas que se prevean para erradicar estas conductas antideportivas deberían superar el juicio de proporcionalidad, mediante sistemas que entronquen con la legalidad y que en sí mismos o en sus modos o formas de ejecución no posibiliten actuaciones vulneradoras de los derechos fundamentales de los deportistas, en especial y por lo aquí tratado, del derecho a la intimidad entendido con amplitud. En otras palabras, el notable reforzamiento del marco legal de la lucha contra el dopaje en el deporte, ha de ser necesariamente cohonestado con el respeto a los derechos y libertades fundamentales del deportista y demás personas intervinientes, requiriendo la protección del derecho a la intimidad del sujeto de una singular atención. Por tanto se ha partir de la siguiente premisa: la lucha contra el dopaje no puede llevarse a cabo de cualquier modo y ha de ser exquisito con todos los derechos del deportista implicado en los controles antidopaje, sin que por ello se produzca merma alguna en la eficacia de dichos controles. En pro de tal eficacia, algunos derechos de los deportistas han de ser objeto de una adecuada ponderación, de modo proporcional a los fines legítimos que se consigan en materia de lucha contra el dopaje.

\section{BiBLIOGRAFÍA}

AA.VV., Derecho deportivo. Legislación, comentarios y jurisprudencia, en Palomar Olmeda, Alberto - Pérez González, Carmen (coordinadores) (Valencia, Tirant lo Blanch, 2013).

AA.VV., Doping and Anti-Doping Policy in Sport: Ethical, Legal and Social Perspectives, en McNamee, Mike - Møller, Verner (editors), (London, Routledge, 2011).

AA.VV., Dopaje, fraude y abuso en el deporte, en Bosch CAPdevila, Esteve - FrandUET Sugrañes, María Teresa (coordinadores), Colección “Derecho y Deporte" dirigida por Antonio Millán Garrido (Barcelona, Bosch, 2007).

AA.VV., Régimen jurídico del dopaje en el deporte, en MiLLÁN GARRIDO, Antonio (coordinador), Régimen jurídico del dopaje en el deporte, Colección "Derecho y Deporte" dirigida por Antonio Millán Garrido (Barcelona, Bosch, 2005).

Armaza Armaza, Emilio José, voz "Bioderecho en Latinoamérica" (jurídico), en Romeo Casabona, Carlos María (director), Enciclopedia de Bioderecho y Bioética (Bilbao - Granada, Cátedra Interuniversitaria de Derecho y Genoma Humano Comares y el Instituto Roche, 2011), I.

Atienza Macías, Elena, Dopaje y enfermedad mental: más allá de la responsabilidad

Mundial Antidopaje de localización permanente de los deportistas para someterles a controles "antidoping" por sorpresa. Véase la noticia completa y los comentarios que suscitó en: http://www.marca.com/2009/01/28/tenis/1233156418.html [última consulta: 15 de marzo de 2013]. 
del deportista, disponible en: http://www.cebid.com.br/ii_sem_hispano_brasileiro/ dra_elena.pdf [última consulta: 15 de marzo de 2013].

Auneau, G., Dopage et mouvement sportif (Voiron, Presses Universitaires du Sport, 2001).

Bandrés Moya, Fernando, voz "Salud" (técnico), en Romeo Casabona, Carlos María (director), Enciclopedia de Bioderecho y Bioética (Bilbao - Granada, Cátedra Interuniversitaria de Derecho y Genoma Humano - Comares y el Instituto Roche, 2011), II.

Bermejo Vera, José, Constitución y Deporte (Madrid, Tecnos, 1998).

Bermejo Vera, José, Régimen jurídico de la prevención y control del dopaje en el deporte, en Romeo Casabona, Carlos María (editor). Más allá de la salud. Intervenciones de mejora en humanos (Bilbao - Granada, Cátedra Interuniversitaria de Derecho y Genoma Humano - Comares, 2012).

Cazorla Prieto, Luis María - Palomar Olmeda, Alberto (directores), Comentarios a la Ley Antidopaje en el Deporte (Pamplona, Aranzadi, 2007).

Cortés Bechiarelli, Emilio, El delito de dopaje (Valencia, Tirant lo Blanch, 2007).

De Miguel Beriain, Iñigo, El poder en la era de la globalización: análisis de una metamorfosis (Granada, Comares, 2008).

Dumas, P. Le doping (Paris, Gazette Médicale de France, 1977).

Gifford, C., Dopaje y deporte (traducción castellana de Manzano Bernárdez, Pablo, Colección ¿̇Y tú?, ¿qué opinas?, No 5, Madrid, Morata, 2010).

Gomara Hernández, José Luis, “Doping”. El régimen jurídico del dopaje (Pamplona, DAPP Publicaciones Jurídicas, 2008).

Hardie, Martin, No va sobre la sangre: Operación Puerto y el fin de la modernidad, en Revista Aranzadi de Derecho de Deporte y Entretenimiento, 30 (Pamplona, Editorial Aranzadi, 2010).

Malo De Molina, Diana, Medicina deportiva (jurídico), en Romeo Casabona, Carlos María (director), Enciclopedia de Bioderecho y Bioética (Bilbao - Granada, Cátedra Interuniversitaria de Derecho y Genoma Humano - Comares y el Instituto Roche, 2011), II.

Molina Navarrete, Cristóbal, Nadal contra los "Vampiros" de la AMA: la lucha por el derecho a la intimidad en la relación deportiva profesional (Monografía Asociada a la Revista Aranzadi de Derecho de Deporte y Entretenimiento, No 5, Pamplona, Aranzadi, 2010).

Molina Navarrete, Cristóbal, Nadal lleva razón, la AMA se extralimita en su control antidopaje: el derecho a la intimidad del deporte profesional autónomo, en Revista jurídica de deporte y entretenimiento: deportes, juegos de azar, entretenimiento $y$ música, 26 (2009).

Nicolás Jiménez, Pilar, La protección jurídica de los datos genéticos de carácter personal (Bilbao - Granada, Cátedra Interuniversitaria de Derecho y Genoma Humano Comares, 2006).

O'Leary, J., Drugs and Doping in Sport. Socio-Legal Perspectives (London, Cavendish Publishing, 2001).

Palomar Olmeda, Alberto - Rodríguez García, José, La saludpública y las medidas que afectan a la misma para la lucha contra el dopaje, en Cazorla Prieto, Luis María - Palomar Olmeda, Alberto (directores), Comentarios a la Ley Antidopaje en el Deporte (Pamplona, Aranzadi, 2007). 
Palomar Olmeda, Alberto, El dopaje en el deporte. Un intento de elaborar una visión sosegada y constructiva, Colección Derecho Deportivo, No 2 dirigida por Alberto Palomar Olmeda (Madrid, Dykinson, 2004).

Pérez González, Carmen - Rodríguez García, José, El contexto internacional de la ley, en Cazorla Prieto, Luis María - Palomar Olmeda, Alberto (directores), Comentarios a la Ley Antidopaje en el Deporte, (Pamplona, Aranzadi, 2007).

Pérez Monguió, José María, Dopaje, animales y competición deportiva”, en Millán Garrido, Antonio (coordinador), Régimen jurídico del dopaje en el deporte, Colección "Derecho y Deporte" dirigida por Antonio Millán GARRIDo (Barcelona, Bosch, 2005).

Pérez Triviño, José Luis, The Challenges of Modern Sport to Ethics From Doping to Cyborgs (New York, Lexington Books, 2013).

Pérez Triviño, José Luis, Ética y deporte (Bilbao, Desclée De Brouwer, 2011).

Prokop, C., Die Grenzen der Dopingverbote (Baden-Baden, Nomos Verlagsgesellschaft, 2000).

Punzón Moraleda, Jesús - Sánchez Rodríguez, Francisco, Una situación ambivalente del derecho de deporte: la luch a contra el dopaje y la defensa del derecho de intimidad, en Revista juridica de deporte y entretenimiento: deportes, juegos de azar, entretenimiento y música, 26 (2009.

Ramos Gordillo, Antonio, El uso de sustancias para la mejora del resultado: de la mitología al fármaco, en Revista jurídica de deporte y entretenimiento: deportes, juegos de azar, entretenimiento y música, 11 (2004).

Ramos Gordillo, Antonio, Lucha contra el dopaje como objetivo de salud, en Adicciones, 11 (1999) 4.

Ramos Gordillo, Antonio. Un problema continuado y sin final: la definición de dopaje, en Revista jurídica de deporte y entretenimiento: deportes, juegos de azar, entretenimiento y música, 11 (2004).

Rodríguez Bueno, Cecilia, De los controles y la responsabilidad de su realización, en Cazorla Prieto, Luis María - Palomar Olmeda, Alberto (directores), Comentarios a la Ley Antidopaje en el Deporte, (Pamplona, Aranzadi, 2007).

Rodríguez García, José, El deber de localización de los deportistas y su derecho a la intimidad: especial referencia al consentimiento, en Revista jurídica de deporte y entretenimiento: deportes, juegos de azar, entretenimiento y música, 31 (2011).

Romeo Casabona, Carlos María, La intimidad y los datos de carácter personal como derechos fundamentales y como bienes jurídicos penalmente protegidos, en ECHANO BASALDÚA, Juan Ignacio (coordinador), Estudios Jurídicos en Memoria de José María Lidón, (Bilbao, Publicaciones de la Universidad de Deusto, 2002).

Romeo Casabona, Carlos María, El médico y el Derecho Penal. La actividad curativa (licitud y responsabilidad penal), (Barcelona, Bosch, 1981), I.

Rubio, Francisco, El dopaje y la normativa de salud laboral, en CAzorla Prieto, Luis María - Palomar Olmeda, Alberto (directores), Comentarios a la Ley Antidopaje en el Deporte (Pamplona, Aranzadi, 2007).

Tamburrini, C., ¿Qué tiene de malo el dopaje? en Dilemata, 2 (2011) 5.

Terrados Cepeda, Nicolás, La salud de los deportistas desde la perspectiva del médico de equipo, en Asís Roig, Agustín de - Hernández San Juan, Isabel (coordinadores), Colección Derecho Deportivo, No 8, dirigida por Alberto Palomar Olmeda (Madrid, Universidad Carlos III - Dykinson, 2006).

Ventas SAstre, Rosa, Eventual delito contra la salud pública: comentario al Auto de 
la Audiencia Provincial de Madrid (sección 5a), de 12 de enero de 2009, por el que se reabre la "Operación Puerto", en Revista Aranzadi de Derecho de Deporte y Entretenimiento, Editorial Aranzadi, 26 (Pamplona, 2009).

Vernet Perna, Beatriz, Delitos relacionados con el dopaje en el deporte, (Madrid, Instituto Universitario de Investigación sobre Seguridad Interior, UNED, 2008). 
